\section{ABSTRACT}

Officially launched just over a year ago, the Open Access Network (OAN) offers a transformative, sustainable, and scalable model of open access $(\mathrm{OA})$ publishing and preservation that encourages partnerships among scholarly societies, research libraries, and other partners (e.g., academic publishers, university presses, collaborative e-archives) who share a common mission to support the creation and distribution of open research and scholarship and to encourage more affordable education, which can be a direct outcome of OA publishing Our ultimate goal is to develop a collective funding approach that is fair and open and that fully sustain the infrastructure needed to support the full life-cycle for the infrastiction of the schorly record, including new comming and Make Knowledge Public.

\section{INTRODUCING THE OPEN ACCESS NETWORK} Sharing, curating, and preserving scholarship are imperative for the
advancement of research. The ready availability of scholarly public central to teaching and learning and optimizes opportunities for innovation
and development across higher education and beyond. Deep fundamental and development across higher education and beyond. Deep fundament
changes to the scholarly communication system are needed not only to changes to the scholarly communication system are needed not only
respond to the numerous funding crises in higher education and to encourage emerging and new forms and formats of scholarship, but also to foster and deepen the connections between the academy and the wider public. Only an approach to scholarly communication that builds collective and collaborative alliances across a wide variety of institutions and that engages a range of stakeholders can provide a
truly open and sustainable forms of scholarship.

The Open Access Network (OAN) offers a bold new model to support or by developing our own preservation archive, but rather by supporting the work and the infrastructure of others. In adopting this strategy, the OAN can be both incremental and forward-thinking: we propose a phased approach that seeks to open up current forms of scholarship (e.g., journals, monographs) while simnllaneously establishing the infrastructure necessary to build, support, and sustain new and emerging modes of
communication. We focus in the first instance on publications and platforms in the humanities and social sciences (HSS), disciplines that are most at risk in the current turbulent cost-per-unit-driven open-access (OA) environment. Even so, our model seeks to develop support mechanisms infrastructure that could be used in the STEM (science, technology,

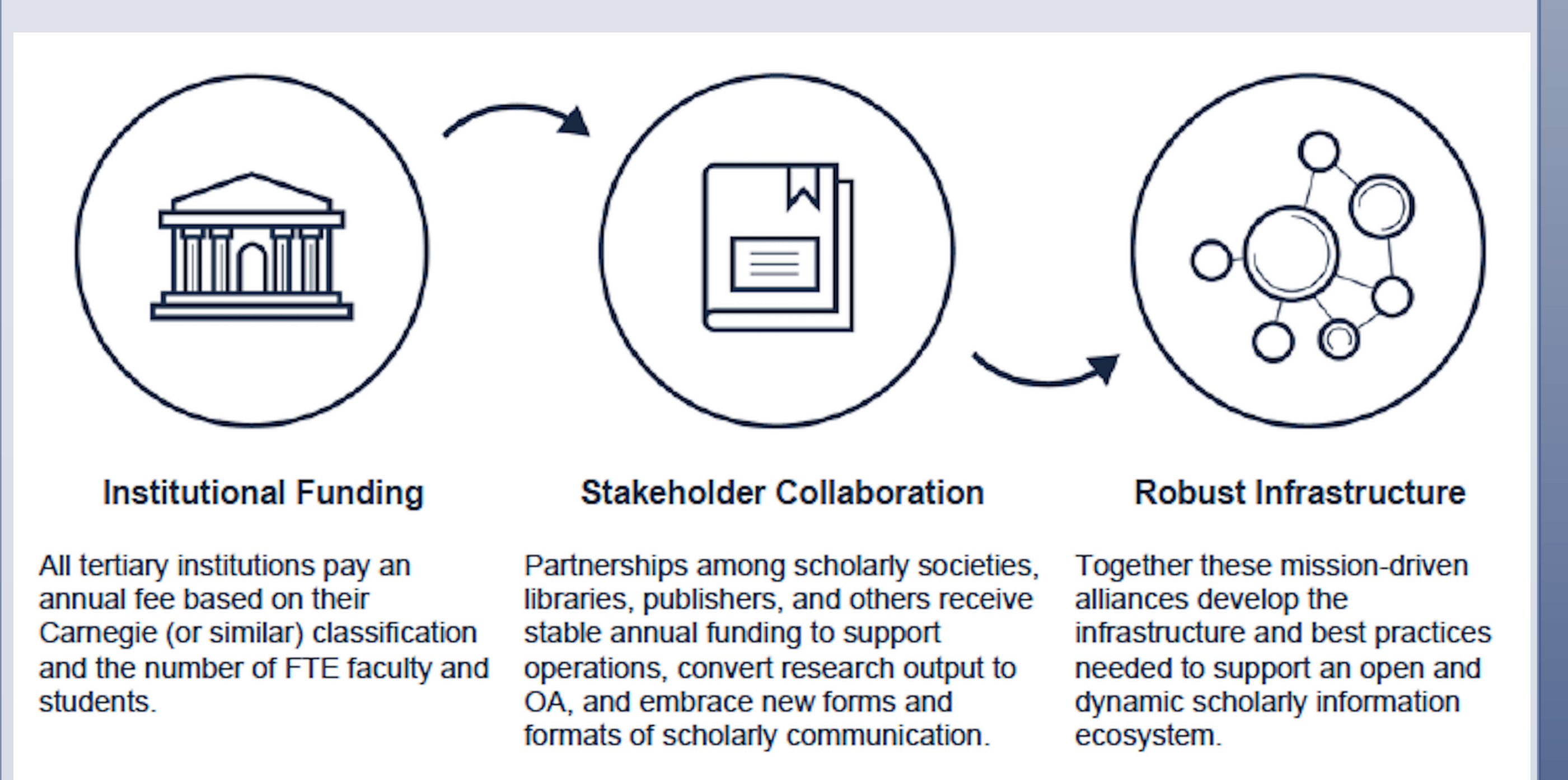

\section{FINANCIAL MODEL}

The OAN financial model is designed to support open scholarly communication infrastructure itself, rather than specific packages (e.g., journals or books), projects, or platforms - an approach that requires a

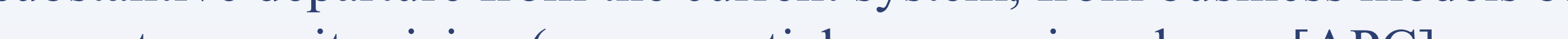
on cost-per-unit pricing (e.g., an article-processing charge $[\mathrm{APC}]$ or a
book-publication charge [BPC]) to a business model that supports the infrastructure and resources needed to create, present, and preserve
scholarly outputs of all kinds. The OAN model proposes that all institutions of higher education contribute to systemic support of the of the economics of $\mathrm{OA}$ by way of partnerships between and amoth scthe economics of OA by way of partnerships between and among scholarly societies/university presses, institutions and their academic
libraries, and publishers that would be funded by an institutional fee structure based on a student-and-faculty per-capita sliding scale. Core to
the model is its insistence on broad, collective institutional support of the the model is its insistence on broad, collective institutional support of the scholarly communication infrastructure itself, not on any particular format (e.g., books, journals, websites).

The idea - originally presented in a 2014 white paper ("A Scalable and Sustainable Approach to Open Access Publishing and Archiving for Humanities and Social Sciences") authored by Rebecca Kennison and Lisa
Norberg — has now been refined to address feedback from stakeholders in terms of the publication partnership inclusion criteria, the funding formula, nd the funding dispersion process; however, the core concepts from that paper remain unchanged.

The centerpiece of the financial model continues to be an annual or multiyear payment that is made by every institution of higher education and that is based on a slding scale by International Standard Classification of Education (ousside the Unic States). Our proposal is to begin with US\$0.50 per student per year of study (ranging from US\$2 per year per student at a community college up to US\$S per student per year at a doctoral-granting institution) and US\$S per full-time faculty. The payment is modest relative to the overall budg results in a sum substatiol enough to sustain a vibrant and open scholoty communication environment. Securing funding from the OAN is comparatively easy. Academic
institutions and scholarly societies (and their publishers) or university presses come together in partnership to apply for funds through a lightweight screening process. Partners must meet these minimum criteria: Collaboration between at least one academic institutional unit (e.g.

* A two-year roadmap that includes plans for growth and product development and that outlines an incresc

Financial transparency between the partners and with the OAN

administrators detailing costs and workflow processes
and

An explicit plan for archiving and preservation

A clear memorandum of understanding between partners that stipulates procedures for modifying, amending, or terminating the partnership The funds dispensed by the OAN are then used to provide direct financial support for the distribution, access, and long-term archival preservation infrastructure of these partnerships and their publications, projects, and platforms.

Once a proposal has received funding, an annual audit will be conducted and a report submitted by the publishing partnership to ensure that the
applicants are meeting their stated goals and that the funds are being use apppropriately.

\title{
FUNDING DISTRIBUTION
}

The OAN will not host any projects ourselves. Instead, the monies collected by the OAN will go to support the scholarly communication
infrastructure itself, whatever the form, format, platform, product, or infrastructure itself, whatever the form, format, platform, product, or
project. Each project by each partnership will appear listed on the OAN funding contribution and distribution site, which will look fanilior to the who use crowdsourced funding sites already. Funding through the OAN (which will come from institutions, foundations, organizations, companies, and individuals) can be designated on a project-by-project basis, on a discipline-by-discipline basis, in support at the level of an area of study fund Because all projects are in certain ways unique, we will not list publicly the amount needed to fund any given individual project.

Transparency between and among the partners as to the annual projectspecific costs is a requirement for OAN funding and so these costs are also known by the OAN administrators, but such project-level financia information could prove difficult to explain succinctly in a public forum societies or presses in the position of having to justify why for want to $p$ they employ a managing editor or pay a vendor for XML markup? We have every reason to believe the partnerships, since they will involve will strive to keep costs as low as possible.

Collaborative Publ
MLA Commons

MLACQMM

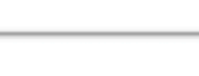

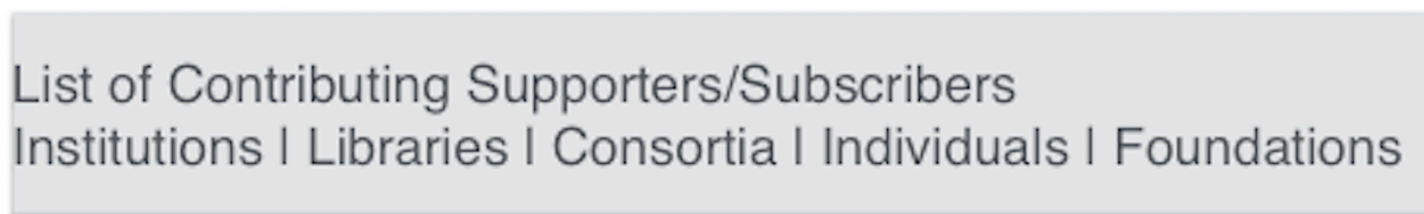

To acknowledge the investment many institutions are already making in OA publications, projects, and platforms, we have factored into the funding formula the option for an institution to reduce its annual payment by the
(self-reported) amount that that institution already spends on other HSS for HSS articles in fully OA journals the Open Library of the Hue APCS Knowledge Unlatched, Luminos, Lever, campus-published journals, ope educational resources, discipline-specific repositories for HSS content digital humanitites projects, and so on.) Acknowledgement of these local OA priorities underscores the importance of institutional support for OA infrastructure whether regional, national, or global.

The remaining balance of the institutional annual fee that is spent directly on OAN-supported projects is dispensed to OAN partner projects
subject disciplines, geographic regions, or publishing form accordance with institutional, funder, or individual donor priotios. Fund are then distributed to cover the costs of the partners' publications.platforms, and projects, providing direct support for the infrastructure and resources needed for the creation, curation, distribution, and long-term archival preservation of scholarly content. Examples of OAN-supported journals, university press-and society-published mentegraphs series, open educational resources, discipline-specific repositories, and innovative digital projects and platforms.

\section{KEY POINTS}

We are looking to institutions, not necessarily to their libraries, to fund this model. Our emphasis is on $\mathrm{OA}$ 's direct educational and societal economic growth that results from ongoing access to research and scholarship.

We are looking for participation from the entire higher education community, from small community colleges and large research

universities alike, eventually at global scale.

- Our approach looks to fund the entire scholarly communication

infrastructure, not simply certain types of research output, supporting
both current and new modes of communication.

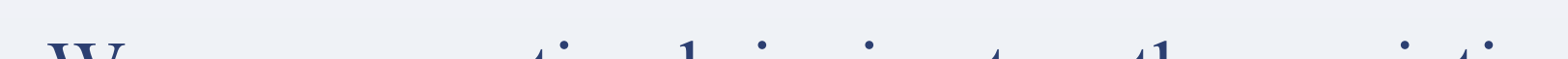

, before, at least not at scale.

We are focusing in the first instance on HSS. Both underfunded and accustomed to paying nothing to publish, scholars in HSS disciplines

require a different approach for $\mathrm{OA}$ to work for then.

Our plan is not bound by national borders but can be adapted, with regional modifications, in all countries by those looking for a more

\section{ABOUT THE OAN}

Kennison, Rebecca, and Lisa Norberg. "A Network Approach to Scholarly Web: http://bit.ly/2cLEzBy

A Scalable and Sustainable Approach to Open Access Publishing and 2014. Web: http://bit.ly/lfLSNrR

"Toward a Scalable and Sustainable Approach to Open Access Publishing and Archiving for Proposal." Learned

Seeley, Alexis, Lisa Norberg, and Rebecca Kennison. "A Scalable and September 2014. Web: http://bit.ly/2cAmD9S



FOR MORE INFORMATION

Rebecca Kennison, Principal and Executive Director

K|N Consultants and the Open Access Network

E-mail: rrkennison@knconsultants.org

Twitter:@OA_Network, @knconsultants

one: +1.347 .746 .5931$

Web: openaccessnetwork.org 